Volume 7

Issue 3 May

Article 11

May 1980

\title{
The Impact of Consumerism on Health Care Change: Alternatives for the Future?
}

Allen W. Imershein

Florida State University

Eugenia T. Miller

Tulane University

Follow this and additional works at: https://scholarworks.wmich.edu/jssw

Part of the Health Policy Commons, Social Policy Commons, and the Social Work Commons

\section{Recommended Citation}

Imershein, Allen W. and Miller, Eugenia T. (1980) "The Impact of Consumerism on Health Care Change: Alternatives for the Future?," The Journal of Sociology \& Social Welfare: Vol. 7 : Iss. 3 , Article 11.

Available at: https://scholarworks.wmich.edu/jssw/vol7/iss3/11 
THE IMPACT OF CONSUMERISM ON HEALTH CARE CHANGE: ALTERNATIVES FOR THE FUTURE?*

\author{
Allen W. Imershein \\ Department of Sociology \\ Florida State University \\ Eugenia T. Miller \\ Department of Sociology \\ Tulane University
}

The quest for consumer participation in the management of health care delivery may have experienced its first signs of success, but the implications of that success are as yet unclear. The establishment of consumer majorities on the newly developed health systems agency (HSA) boards was seen as an important milestone in the development of the consumer movement in America over the last ten years. The initial wave of optimism over the Great Society programs that in part gave birth to the consumer movement has long since vanished, but some of the organizational results of those attempts at innovation have become routinely established, as the requirements for consumer participation specified in wave after wave of health related amendments clearly indicates. But what are the results of this participation, and what can we reasonably expect in the future?

Many of the initial problems of consumer involvement remain with us, especially where lay consumers and expert professionals serve together in the same organizational setting, as is typically the case. Providers dominate decision-making despite the presence of consumer majorities on decision-making bodies. Critics have questioned the naivete which suggested that simple consumer involvement would provide some measure of public accountability. Evidence thus far

* Revised version of a paper presented at the Annual Meeting of the Southern Sociological Society, April, 1977. 
clearly demonstrates that such is not the case (Navarro, 1973; Metsch and Veney, 1976). Critics have also suggested, however, that these problems are not insurmountable and that, with some revisions in the program for consumer participation, the power and control may shift from the provider to the consumer realm, as consumer ideology has all along claimed it should. The discussion to follow will argue that even if the problems of participation are surmounted and if consumers do gain greater control of relevant boards and councils, the net effect will not be to shift control of health care organization from providers to consumers. Rather, given the present organizational arrangements and opportunities, the effect would be to shift the control of health care delivery from one group of providers to another.

\section{The Uncertain Growth of Consumerism in Health Care}

The growth of consumerism in American society has sometimes been hailed as a new social movement (Reeder, 1972). Sparked by the emergence of consumer involvement in OEO-sponsored neighborhood health centers, the development of the movement in health care has been fostered by the beginning redefinition of roles -- from doctor-patient to provider-consumer, by a shift in concern from curative and crisis care to preventive care, by the change from solo practice to bureaucratic models for delivery which more readily provide organizational avenues for consumer involvement, and, of course, by the overall legislative support granted to consumer participation (Reeder, 1972; Milio, 1974). But the organizational success thus far has been mixed at best (Stoller, 1974; Metsch and Veney, 1976; Douglass, 1975). Consumers may have moved into the decision-making realm, but their impact within this realm has been limited. The factors which have been cited to explain this limited impact can be grouped into three main categories.

First, consumers have been seen as largely unprepared for their new roles. Despite the fact that they are now labeled "consumers" rather than "patients", they tend to regard the providers as the only ones having the necessary expertise to make important 
decisions. Thus, whatever viewpoint they may bring to the setting, that perspective becomes coopted in favor of that of the providers. Moreover, consumers are often inexperienced in speaking out in committee contexts and therefore less able to articulate a position which might be controversial (Stoller, 1974). Finally, the extent to which consumers have a clearly legitimated role to take the control which their majority status would make possible is at best unclear (Maxmen, 1976).

Second, providers have a clearly vested interest in maintaining control in all organizational settings which affect their everyday work practices. Participation on committees is viewed as one part of already well-defined professional roles in contrast to the largely voluntary status of consumers. Providers may be willing to allow consumer input over relatively minor issues, but will structure committee action in such a way as to defer or define in their own terms issues of critical concern (Milio, 1974; Stoller, 1975; cf. Bachrach and Baratz, 1970; Warren et a1, 1974).

Third, a number of "system" characteristics would tend not to encourage the development of consumer strength. The legislative mandate, though clearly placing consumers in a majority status, failed to define clear role activities for that participation (Metsch and Veney, 1976). Existing resources which might be used in decision-making are much more available to providers than consumers. Few situations outside the immediate context provide occasions in which consumers might coalesce into an organized group or articulate proposals and arguments, i.e., the organizational superiority of providers is clearly evident.

Finally, the placement of consumers on advisory and management boards serves to legitimate the continued decision-making of these groups without necessarily changing the character of the decisions or important decision-makers. Thus, weak consumer participation contributes to the maintenance of the "system" without fundamentally changing it (Navarro, 
1973; 1976). Consumer participation, as Metsch and Veney (1976) suggest, is indeed good politics.

Critical commentaries on the problems of consumer participation have also proposed a number of solutions to aid that process (Young, 1975; Stoller, 1974; Milio, 1974; Friedson, 1970). The development of organizational and leadership experiences for consumers is seen to be crucial. Resources need to be made more available. Tasks need to be better defined. Further legislation needs to set forth clear role responsibilities. Providers need to be persuaded of both the importance and usefulness of more than token consumer participation. The legitimation of consumer decisionmaking as an inherent right needs to be solidly established. And consumers need to be better educated, better organized and more certain of their own investment in these new organizational roles (Illich, 1976).

\section{Structural Barriers to Change}

Despite the optimism conveyed by those supporters of consumer based programs, the variety of proposed resolutions to problems of consumer participation must finally be seen as naive and largely superficial. To be sure, the development of resources, specified roles, leadership experience, provider indulqence, and the like, will make for a stronger consumer voice on decision-making boards. But what will be the position spoken for in this newly-gained realm? Arguments rejecting provider dominance assume that consumers have a well-defined and agreed upon position from which to speak. Evidence suggests the contrary. Consumers disagree widely over who should engage in decisionmaking activities, how much government should be involved in the financing of health care, and whether there is even a problem to be dealt with (Strasmann, 1975). Moreover, this disagreement over major issues may reflect a more fundamental factor explaining the lack of consumer consensus: the lack of a structural base which could unify consumer interests and organize their efforts. 


\begin{abstract}
Alford (1975) has argued that the current health care controversy can be understood as reflecting political and organizational maneuvering among longstanding structural interests, which represent professional, legislative, and cultural institutional arrangements. The professional monopoly of private physicians, their organizations, and the laws and customs surrounding their activities constitute the major structural interest which has dominated American health care for the last fifty years. The changing technology and division of labor in health care in recent years created basic conflicts with these dominant practices and has yielded a second structural interest based on hospitals, public health and health planning organizations, and the corporate sector supporting much of these activities. Indicative of this new structural interest has been the emergence of a bureaucratic reform movement calling for an end to fragmented care, for greater coordination and integration of services, and for more continuity and comprehensiveness in the provision of care, all of which would be enhanced by better management and regulation, i.e., the development of bureaucratic medicine (Mechanic, 1976). Alford recognizes a third structural interest, that of the consumer population, but he characterizes it as repressed, for "no social institutions or political mechanisms in the society insure that these interests are served" (1975:15). Consumers may have power in numbers, but without an institutional base which would serve to recognize those numbers, they are unlikely to affect the present system.
\end{abstract}

Warren's (1974) data on community decision organizations provides some additional confirmation for Alford's perspective. These organizations by and large focused on delivery of services to what was seen as a poverty population in need of aid. Even without the provision of explicit rules, the dominant "institutionalized thought structure", as Warren calls it (similar to Alford's structural interests), provided for consistent action across both differing organizations and differing cities. When a challenge was mounted against this dominant structure, and power was shifted to a new group, the activities carried out in the newly controlled organizational settings differed little from those of the previous group, despite an outpouring of ideological rhetoric. In other words, 
lacking a concrete strategy for action, challenging groups tended to redefine the problem in terms of existing means for "problem-solving". In similar fashion, the consumer movement in health care may be little more than good rhetoric for those out of power and good politics for those who are in.

\section{Possible Alternatives}

The explanation we have provided above may prove tempting to both critical and cynical observers of the American political and health care scenes. Though it is undoubtedly more accurate than the largely optimistic viewpoints noted earlier, it may at the same time deny an important aspect of the consumer movement in health care. Although we have argued that health care consumerism consists mainly of ideology and lacks a structural base, the movement is not totally without substance. But the substantive nature of the arguments proposed by consumer advocates may lead along different paths than those advocates presume. These arguments divide the advocates into two broad and not necessarily overlapping groups. That the two groups may have ultimately conflicting goals (cf. Starr, 1976) makes it essential that further research and discussion take note of the distinguishing characteristics.

The first group is the most vocal and pushes the most heavily for fundamental change (see for example, Heal Yourself or The American Health Empire). Their arguments focus upon the continuing health care crisis, in particular, the maldistribution of resources -hospitals, physicians and the like, the fragmentation of the health care system, the improper locus of control, the search for profits, the conflict of interest positions of providers, the discrimination against the poor and racial minorities. Not all critiques name all these elements, by any means, but there is considerable overlap. As an alternative to the present system, most of the above elements need to be reversed. The health care system needs to be accessible and responsive to consumers, and consumers need to be in decision-making positions to insure that possibility. The system needs to be organized to provide coordinated care that is comprehensive in 
nature; preventive as well as crisis care; providers need to be removed from conflict of interest positions, and the profit-making motive needs to be eliminated. How is all this to be accomplished? Presumably the development of a consumer-oriented, consumer controlled system would do just that. But is this claim anything more than ideological rhetoric with no possibility of occurrence as Alford and others suggest?

If it is more than rhetoric, then the fulfillment of these claims will likely not take the course entirely consistent with the proposed arguments. It is striking that proposals for change emerging from the consumer movement are very similar to those from the bureaucratic reform movement noted earlier: a critique of the fragmented and maldistributed system; a call for greater integration, coordination, comprehensiveness, and continuity of care, i.e., calls for better regulation and management of the current system. Given the nature of the proposed changes and the size and complexity of the current system, it is unlikely that anyone other than a managerial group, i.e., the "corporate bureaucrats", would take charge of such changes. Thus in both rhetoric and effect, this aspect of the consumer movement can be seen as no more than an extension of the already ongoing bureaucratic reform movement (Navarro, 1973, 1976). The process of change might supply more roles for consumers than ever before, but the substance would result in a shift of power not to the consumers, but instead from one group of providers, the professional monopolists, to another, the corporate bureaucrats. In that sense, the consumer movement is good politics indeed.

The second group in the consumer movement may seem less vocal than the first. They comprise the varied ranqe of participants in what might be called the selfcare movement (see especially Levin et al, 1976). Their major thrust is not toward changing the current health care system, but toward minimizing the need for it. Whatever the organizational strengths or weaknesses of the current system, it is seen by this group as oriented toward sick care rather than health. In contrast to the professionally based expertise requisite for the sick care system, the wellness orientation of the self care movement emphasizes lay 
responsibility, both individual and group (Carlson, 1975). Such an orientation is manifest in the feminist health center development, the emergence of some of the free clinics, and growth of nutritional awareness and interest in "health foods", and the calls for reliance on the natural healing powers of the body and the promotion of natural ways of living and interacting with one's environment (see e.g., Samuels and Bennett, 1973; The Boston Women's Health Collective, 1972; see also Levin et a1, 1976: 94-114 for annotated bibliography) .

The self-care movement, if it is yet in fact a movement (Levin et al, 1976: 31ff), must be distinguished from a broader ideology which has recently gained considerable currency. On the one hand this ideology, exemplified by the arguments of Ivan Illich (1976), rejects the medical care system in toto as doing more to cause than to cure sickness, a view congruent with an earlier "therapeutic nihilism" (cf. Starr, 1976). On the other and complimentary hand, it emphasizes the importance of individual reliance and self-help groups, here construed more broadly than an application solely to health. This ideology has been roundly criticized for its rejection of considerable successes in the medical care system, its conflicting goals for better health, and its uninformed attitude toward larger structural issues affecting health (Fox, 1977; Starr, 1976; Sidel and Sidel, 1976; among many).

Whatever strength exists in the self-care movement does not lie in the strident ideology noted above, however, but in a set of day-to-day practices which emphasize the growth and utilization of lay medical knowledge rather than the rejection of professional expertise and the centrality of individual responsibility and life-style choices rather than the irrelevance of the medical care system. The extent to which professional knowledge and the medical care system are de-emphasized results from an awareness that a reliance on these does not necessarily promote health but primarily cures sickness. Such a stance is consistent with long-standing public health and a recent more general perception of the relative lack of impact of the medical care system on health levels of the population in comparison with broader social and 
environmental changes (see e.g., Lalonde, 1974; Fuchs, 1974; Levin et al, 1976; Task Force on Preventive Medicine, 1976; Daedalus, Winter, 1977, passim).

The efforts of this group parallel a growing shift from curative medicine to preventive medicine with attendant emphasis on health education and health promotion at an early age (cf. Carlson, 1975). While curative medicine relegates the consumer to the passive role of patient, preventive medicine promotes an active orientation toward personal health maintenance (Morse, 1979). There is ample evidence that such a shift is occurring. For example, efforts to curtail smoking, the rapidly growing interest in exercise, breast selfexaminations, among others, point to an increased acceptance of personal responsibility for maintaining one's own health. This movement is further highlighted in the diffusion of medical technology to lay consumers as evidenced in the marketing of self-administered pregnancy test kits and personal blood pressure cuffs that allow for self-monitoring. Relatedly, current efforts to minimize environmental health hazards, both within the work environment as well as in the broader environment, speak to a burgeoning consumer concern with averting future health hazards. Recent organized protests against continued operation and new building of nuclear power plants have dramatized such active concerns. We suggest that this new kind of consumer activism, both in the promotion of self-care and in the prevention of environmental health hazards, is gaining broad socio-cultural support. By and large, these efforts may mark the beginning of an undermining of what Starr (1978: 177) has called the "cultural authority of medicine".

Given this more personalized orientation, it is surprising that its advocates are not seen in the forefront of those working for change in the current medical care system. However, this latter branch of the consumer movement may have more long-range impact than the former. For unlike the former, this group is based on a set of everyday practices closely related to changing attitudes about health maintenance around which a strong and coherent movement could arise. It is the new practices which may prove essential in any significant social change (cf. Imershein, 1977a, 1977b) 
Its declaration of relative independence from the current system, while not totally rejecting it, may serve to provide greater possibilities for the development of power than one which attempts to modify the system. The success of such a movement would not be registered by organizational changes which could be co-opted by more powerful groups, as would be the case with the organizational reform group noted earlier. Its co-optation by the current system, if possible, might register its success: the redistribution of specialized medical knowledge and responsibility for health. Thus the impact could be more broadly cultural and more clearly longrange. It may resemble the previous turn of the century medical revolution which took more than 30 years to accomplish, while at the same time reversing the flow of knowledge accomplished by that revolution. In this respect it may be seen as the development of a new approach to health care which may in the end impact the existing organization of health care delivery by gradually diffusing its power base and thus weakening the existing professional monopoly. 


\section{References}

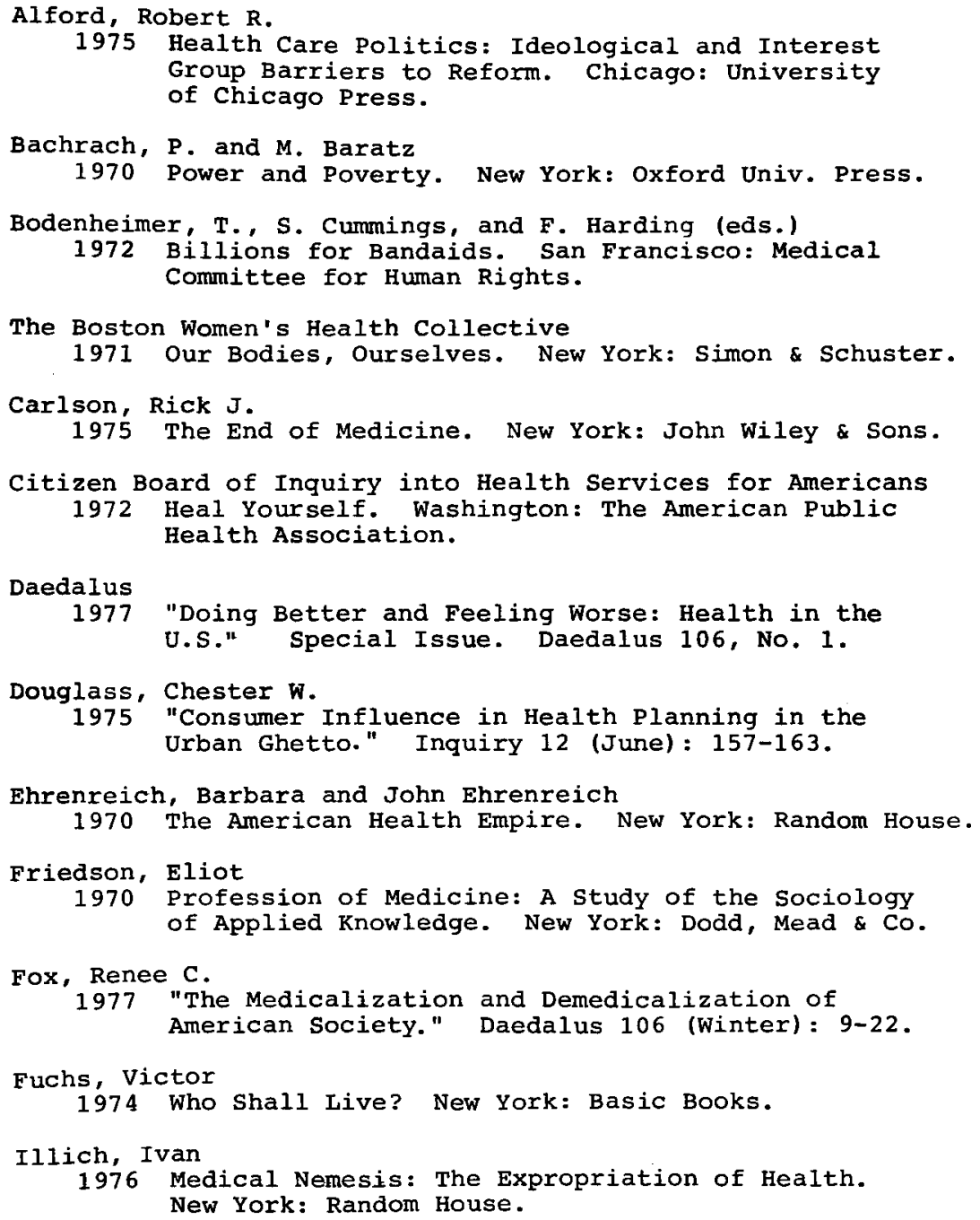


Imershein, Allen $\mathrm{W}$.

$1977 a$ "The Epistemological Bases of Social Order: Toward Ethnoparadigm Analysis." Chapter 1 (pp 1-51) in David Heise (ed.), Sociological Methodology 1977. Washington: Jossey-Bass.

$1977 b$ "Organizational Change as a Paradigm Shift." Sociological Quarterly 18 (Winter): 33-43.

Lalonde, Marc

1974 A New Perspective on the Health of Canadians. Ottowa: Canadian Ministry of National Health and Welfare.

Levin, Lowell S., Alfred H. Katz and Erik Holst

1976 Self-Care: Lay Initiatives in Health. New York: Prodist

Maxmen, Jerrold s.

1976 The Post-Physician Era. New York: John Wiley and Sons

Mechanic, David

1976 The Growth of Bureaucratic Medicine. New York: John Wiley and Sons.

Metsch, Jonathan $M$. and James $E$. Veney

1976 "Consumer Participation and Social Accountability." Medical Care 14 (April): 282-293.

Milio, Nancy

1974 "Dimensions of Consumer Participation and National Health Legislation." American Journal of Public Health 64 (April): 357-363.

Morse, Edward V.

1979 "The Future Development of Preventive Medicine." Unpublished manuscript. Tulane University, New Orleans, Louisiana.

Navarro, Vicente

1973 "National Health Insurance and the strategy for Change." Health and Society 51 (Spring):223-251.

1976 "The Political and Economic Determinants of Health Care in Rural America." Inquiry 8 (June): 111-121. 
Reeder, Leo G.

1972 "The Patient-Client as Consumer: Some Observations on the Changing Professional-Client Relationship." Journal of Health and Social Behavior 13 (December) : 406-412.

Samuels, Mike and Hal Bennett

1973 The Well Body Book. New York: Random House.

Sidel, Victor $W$. and Ruth Sidel

1976 "Beyond Coping." Social Policy 7: 67-69.

Starr, Paul

1976 "The Politics of Therapeutic Nihilism."

Hastings Center Report (October): 24-30.

1978 "Medicine and the Waning of Professional

Sovereignty." Daedalus 107 (Winter): 175-194.

Stoller, Eleanor Palo

1974 "New Roles for Health Consumers: A Study in

Role Transformation." Paper presented to the

American Sociological Association. August.

Stratmann, William, et al

1975 "A Study of Consumer Attitudes about Health Care: The Control, Cost, and Financing of Health Services." Medical Care 13 (Aug):659-668.

Task Force on Preventive Medicine

1976 Preventive Medicine USA. New York: Prodist.

Warren, Roland L., Stephen M. Rose and Ann F. Bergunder

1974 The Structure of Urban Reform. Lexington:

D.C. Heath and Company.

Young, Kue

1975 "Lay-Professional Conflict in a Canadian Community Health Center: A Case Report." Medical Care 13 (November): 899-904. 